20 Corresponding author: Dr. Yi Huang, 805 Sherbrooke Street West, Montreal, Quebec,

21 H3A 0B9, Canada. Email: Yi.Huang@mcgill.ca

22

\section{Is There A Stratospheric Radiative Feedback in Global} Warming Simulations?

Yi Huang, Minghong Zhang, Yan Xia

Department of Atmospheric and Oceanic Sciences, McGill University, Montreal, Canada Yongyun $\mathrm{Hu}$ Department of Atmospheric and Oceanic Sciences, Peking University, Beijing, China Seok-Woo Son

School of Earth and Environmental Sciences, Seoul National University, Seoul, South

Korea

March, 2015 


\section{Abstract}

24 The radiative impacts of the stratosphere in global warming simulations are

25 investigated using abrupt $\mathrm{CO}_{2}$ quadrupling experiments of the Coupled Model Inter-

26 comparison Project phase 5 (CMIP5), with a focus on stratospheric temperature and

27 water vapor. It is found that the stratospheric temperature change has a robust bullhorn-

28 like zonal-mean pattern due to a strengthening of the stratospheric overturning

29 circulation. This temperature change modifies the zonal mean top-of-the-atmosphere

30 energy balance, but the compensation of the regional effects leads to an insignificant

31 global-mean radiative feedback $\left(-0.02 \pm 0.04 \mathrm{~W} \mathrm{~m}^{2} \mathrm{~K}^{-1}\right)$. The stratospheric water vapor

32 concentration generally increases, which leads to a weak positive global-mean radiative

33 feedback $\left(0.02 \pm 0.01 \mathrm{~W} \mathrm{~m}^{2} \mathrm{~K}^{-1}\right)$. The stratospheric moistening is related to mixing of

34 elevated upper-tropospheric humidity, and, to a lesser extent, to change in tropical

35 tropopause temperature. Our results indicate that the strength of the stratospheric water

36 vapor feedback is noticeably larger in high-top models than in low-top ones. The results

37 here indicate that although its radiative impact as a forcing adjustment is significant, the

38 stratosphere makes a minor contribution to the overall climate feedback and its

39 uncertainty in CMIP5 models.

40

41 Key words: Stratosphere, radiative feedback, CMIP5 


\section{1. Introduction}

45 It is increasingly recognized that the stratosphere plays an important role in

46 climate change. In addition to aspects such as the dynamical coupling to the tropospheric

47 circulation (Gerber et al., 2012), the importance of the stratosphere is manifested in its

48 impact on the radiation energy budget. Many stratospheric trace gas species, such as

49 carbon dioxide, ozone, and water vapor, affect the radiation energy balance by interacting

50 with the shortwave solar radiation and the longwave terrestrial radiation. Numerical

51 experiments show that stratospheric contributions are critical for the climate system to

52 maintain the balance of the top-of-the-atmosphere (TOA) radiation energy budget during

53 transient climate change (Huang 2013a). For example, the magnitude of the overall time-

54 varying stratospheric effect on the outgoing longwave radiation (OLR) can be

55 comparable to that of the overall longwave cloud feedback, and the inter-model spread is

56 as large as that of the overall non-cloud tropospheric feedback (Huang 2013b).

57 A climatic effect can be generally classified either as a forcing, which drives

58 climate change, or a feedback, which determines the sensitivity (i.e., how strongly the

59 climate system responds to a given forcing). With regard to the stratospheric radiative

60 effect, especially that related to temperature variations, the conventional view is that it is

61 a forcing effect that arises from the rapid temperature adjustment driven by the radiative

62 cooling due to greenhouse gas perturbation (e.g., Hansen et al. 1997). Interestingly, even

63 when greenhouse gas concentrations are identically prescribed, there may still be

64 substantial inter-model differences in the temperature adjustment and thus in the overall 
65 strength of the adjusted radiative forcing (Zhang and Huang 2014). Hence, there is a need

66 to explicitly assess the stratospheric radiative effect in climate feedback analysis.

67 On the other hand, some studies have hypothesized that stratospheric changes

68 may be coupled with tropospheric and surface climates, and constitute a radiative

69 feedback mechanism (Gerber et al., 2012; Dessler et al., 2013). For instance, the

70 stratospheric overturning circulation, the so-called Brewer-Dobson Circulation (BDC), is

71 projected to intensify in response to global warming (e.g., Butchart et al. 2006; Li et al.

72 2008; Manzini et al., 2014). This may affect both the stratospheric temperature, by

73 enhancing the adiabatic cooling in the tropics and the warming in the extratropics, and the

74 stratospheric water vapor, by modifying the troposphere-stratosphere transport

75 (Feuglistaler et al. 2014). Stratospheric water vapor not only directly affects radiation

76 budget by trapping outgoing radiation but also radiatively cools the stratosphere and thus

77 may induce an indirect (Planck) effect. This process has been hypothesized as a

78 stratospheric water vapor feedback (Forster and Shine 1999; Stuber et al. 2001; Joshi et

79 al. 2010; Huang 2013b; Dessler et al. 2013).

80 It is of great interest to know whether a stratospheric feedback exists in the

81 climate models and whether it affects climate sensitivity in a significant way. However, it

82 is difficult to partition the overall effect to forcing and feedback during transient climate

83 change (Huang 2013b). In this paper, we take advantage of the abrupt quadrupling $\mathrm{CO}_{2}$

84 experiments of CMIP5 (Taylor et al. 2012) to separate the two effects, and focus on the

85 effect that may constitute a feedback. In the following sections, we first explain the 
86 kernel method that is used to quantify the radiative effect of stratospheric temperature and

87 water vapor responses. Then we examine the stratospheric responses and quantify the

88 resulting feedback in the models in the quadrupling $\mathrm{CO}_{2}$ experiment. To diagnose the

89 possible causality, a set of experiments are conducted using the CAM5 model of the

90 National Center of Atmospheric Research (NCAR). We then conclude the paper with a

91 summary and discussion of the main findings.

92

93 2. Method

94 We measure a radiative effect, either forcing or feedback, by the radiative kernel

95 method:

$96 \Delta R_{X}=\frac{\partial R}{\partial X} \Delta X$

97 Here $\frac{\partial R}{\partial X}$ is a set of pre-calculated radiative sensitivity kernels (Shell et al. 2008) and $\Delta X$

98 the change in a climatic variable, e.g., stratospheric temperature or water vapor

99 concentration.

100 To separate the stratosphere from troposphere, we set the tropopause level as the

101 lowest level where the temperature lapse rate is less than $2 \mathrm{~K} / \mathrm{km}$ for a depth of more than

$1022 \mathrm{~km}$ in each grid box in each model following the standard definition of the World

103 Meteorological Organization (WMO 1957). The stratospheric radiative effect is then

104 integrated from the determined tropopause level to the model top. This analysis is done

105 globally at every grid box and for each month.

106 The feedback parameter is defined as 
$107 \quad \lambda_{X}=\frac{<\Delta R_{X}>}{<\Delta T_{S}>}$

108 where $<\ldots>$ denotes global average and $T_{\mathrm{s}}$ is the surface temperature. This parameter is of

109 interest because it is directly related to the climate's overall sensitivity to radiative

110 forcing.

111 The kernel-based feedback analysis procedure is well documented in the literature

112 (Soden and Held 2006, Soden et al. 2008, and Shell et al. 2008). In addition, Huang

113 (2013b) and Huang and Zhang (2014) advanced the method to account for forcing

114 uncertainty in the procedure. The feedback analysis conducted here follows that of Huang

115 and Zhang (2014).

116 Although the kernel method has been validated and mostly used for quantifying

117 tropospheric radiative feedback, our tests show that it is an appropriate method for

118 quantifying the stratospheric feedback as well. Firstly, using a radiative transfer model

119 and based on different types of standard atmospheric profiles (McClatchey et al. 1972),

120 the linearity of radiation response to stratospheric temperature and water vapor

121 perturbations is verified. Fractional errors are less than $15 \%$ when approximating the

122 radiation flux change caused by up to $20 \mathrm{~K}$ stratospheric temperature change by scaling

123 the radiation flux change due to $1 \mathrm{~K}$ temperature perturbation, and are less than $25 \%$

124 when approximating the radiation change caused by quadrupling water vapor

125 concentration by scaling the radiation change due to $20 \%$ water vapor perturbation (20-

126 fold magnification in each case). It is worth noting that the temperature and water vapor

127 changes that we are concerned with (see the following section) do not exceed these 
128 magnitudes. In addition, as found in previous studies (Huang et al. 2007; Zhang and

129 Huang 2014), the stratospheric and tropospheric feedback is linearly additive. The

130 difference between the sum of the radiation changes caused by tropospheric and

131 stratospheric changes respectively and the radiation change caused by both changes

132 simultaneously is generally within a few percent. Secondly, in order to assess the kernel

133 uncertainty associated with model atmosphere and radiation code, we compare the

134 feedback analysis results using two sets of kernels: one based on a NCAR model (Shell et

135 al. 2008) and the other based on a Geophysical Fluid Dynamics Laboratory (GFDL)

136 model (Soden et al. 2008). Although the GFDL model-based kernels do not cover the

137 portion of the stratosphere above $30 \mathrm{hPa}$, the quantifications of $\Delta R_{X}$ (Eq. 1) for the

138 portion below $30 \mathrm{hPa}$ using the two sets of kernels are in good agreement, with a bias

139 generally less than $10 \%$. In summary, these test results suggest that the kernel-based

140 linear decomposition can achieve a comparable accuracy for the stratospheric

141 temperature and water vapor feedback as for the tropospheric feedback (Soden et al.

142 2008).

143

\section{3. CMIP5 $\mathrm{CO}_{2}$ quadrupling experiment}

145 To isolate the feedback from forcing, we analyze the climate change simulated by

146 the CMIP5 models in two idealized quadrupling $\mathrm{CO}_{2}$ experiments: abrupt4 $\mathrm{xCO}_{2}$ and

147 sstClim $4 \mathrm{xCO}_{2}$. In the abrupt4xCO2 experiment, the general circulation models (GCMs)

148 are integrated for 150 years after the atmospheric $\mathrm{CO}_{2}$ concentration is instantaneously 
149 quadrupled. A total of 11 models, as listed in Table 1, are available and included in this

150 study. In the accompanying sstClim $4 \mathrm{xCO}_{2}$ experiment, the GCMs are integrated for 30

151 years with the sea surface temperature (SST) being fixed after the quadrupling. Among

15215 models archived in the CMIP5, 11 models are used for the analysis and compared with

153 the abrupt4xCO2 experiments (see Table 1).

154

$155 \quad 3.1$ Forcing adjustment

156 The change in a stratospheric temperature in the $\mathrm{sstClim} 4 \mathrm{xCO}_{2}$ experiment in

157 relevance to its control run (the sstClim experiment) defines the forcing adjustment

158 response. Figure 1 (top panel) shows that the stratospheric temperature adjustment settles

159 very rapidly. In the sstClim $4 \mathrm{xCO}_{2}$ experiment, the stratospheric temperature drops

160 considerably; most of the cooling is attained within a year and then the temperature

161 steadies, allowing it to be considered a rapid adjustment of the forcing (Hansen et al.

162 1997). The multi-model global mean forcing adjustment, assessed according to Equation

1631 , is $1.9 \mathrm{~W} \mathrm{~m}^{-2}$, compared to the instantaneous forcing of $5.4 \mathrm{~W} \mathrm{~m}^{-2}$ caused by the $\mathrm{CO}_{2}$

164 quadrupling. We notice that the magnitude of temperature adjustment differs substantially

165 across the models, which results in quantitative differences in their adjusted radiative

166 forcing (Zhang and Huang, 2014). The inter-model spread (max-min) among 11 models

167 amounts to $30 \%$ of the mean.

1693.2 Stratospheric temperature feedback 
171 panel), stratospheric temperature continues to vary over the whole integration period (150

172 years) in many models. Because the radiative relaxation time in the stratosphere is short

173 (as manifested by the temperature response shown in the top panel of Figure 1), the

174 extended stratospheric temperature change cannot be understood as a forcing adjustment,

175 but a response that likely relates to SST changes.

176 When the radiation anomaly caused by stratospheric changes in humidity or

177 temperature, quantified using Equation 1, is plotted against the global annual mean

178 surface temperature anomaly, significant correlation is observed in most models. This

179 verifies a strong connection between the surface temperature and the stratospheric

180 radiative effect under question, and justifies quantifying the stratospheric feedback using

181 Equation 2, as commonly done for tropospheric feedback.

182 We first calculate the temperature response that can be considered as a feedback

183 as the average of the last ten years (141-150) of the abrupt $4 \mathrm{xCO}_{2}$ experiment minus

184 forcing adjustment as quantified above in sstClim $4 \mathrm{xCO}_{2}$ experiment. Figure 2 shows the

185 zonal-mean pattern of the feedback response of temperature and water vapor. A bullhorn

186 pattern with positive changes extending from subtropical upper troposphere both upward

187 and poleward is noticed in most of the models (see the mean of model ensemble, MME).

188 We then calculate the feedback parameter according to Equation 2 (see Table 1).

189 The feedback response of stratospheric temperature consists of both positive and negative

190 changes (Figure 2a). The bullhorn temperature response pattern leads to a distinct zonal 
191 mean feedback pattern especially in the mid-latitudes (Figure 3a). Although the feedback

192 at every latitude zone is generally robust and different from zero, its global integration

193 results in a weak global mean feedback parameter, $\lambda_{\text {Tst }}$. The multi-model ensemble mean

194 of $\lambda_{\text {Tst }}$ is $-0.02 \mathrm{~W} \mathrm{~m}^{-2} \mathrm{~K}^{-1}$ with a standard deviation (STD) of $0.04 \mathrm{~W} \mathrm{~m}^{-2} \mathrm{~K}^{-1}$, and a range

195 from $-0.09 \mathrm{~W} \mathrm{~m}^{-2} \mathrm{~K}^{-1}$ (MRI-CGCM3) to $0.04 \mathrm{~W} \mathrm{~m}^{-2} \mathrm{~K}^{-1}$ (IPSL-CM5A-LR). These results

196 suggest that the global mean temperature feedback in the models is rather uncertain.

$198 \quad 3.3$ Stratospheric water vapor feedback

199 Figure $2 \mathrm{~b}$ shows the feedback response of the stratospheric water vapor in the

200 abrupt $4 \mathrm{xCO}_{2}$ experiment. The water vapor response reaches 4 times the unperturbed

201 climatological values in many models. The feedback parameter, $\lambda_{W V s t}$, quantified by the

202 kernel method (Equation 1) has a multi-model mean value of $0.02 \mathrm{~W} \mathrm{~m}^{-2} \mathrm{~K}^{-1}$ and a

203 standard deviation of $0.01 \mathrm{~W} \mathrm{~m}^{-2} \mathrm{~K}^{-1}$ (Table 1). It is interesting to note that because the

204 OLR sensitivity to water vapor $\left(\frac{\partial R}{\partial q}\right)$ changes sign from lower to upper stratosphere, a

205 uniform moistening in the stratosphere would lead to a small overall radiative effect after

206 compensation, such as in tropical regions (see Figure 3b).

207 When grouping the models according to their model top height, we find that the

208 high-top (higher than $1 \mathrm{hPa}$ ) ones show noticeably stronger water vapor feedback (see

209 Table 1). From the water vapor response pattern (Figure 2b), it is evident that the high-

210 top models tend to simulate a relatively stronger lower stratospheric moistening in the 
211 extratropical regions. This leads to a substantial $\left(>0.2 \mathrm{~W} \mathrm{~m}^{-2} \mathrm{~K}^{-1}\right)$ feedback in these regions

212 (Figure 3b).

213 It is worth noting that stratospheric water-vapor feedback parameter shown in

214 Table 1 is an order of magnitude smaller than the value reported by Dessler et al. (2013):

$2150.3 \mathrm{~W} \mathrm{~m}^{2} \mathrm{~K}^{-1}$. A few reasons may explain the difference. Firstly, the feedback evaluated

216 here is defined with respect to the TOA radiation flux while that of Dessler et al. is

217 evaluated at the tropopause. Stratospheric water vapor increases, by itself, would induce a

218 greater change in downwelling radiation at the tropopause $\left(\mathrm{R}_{\mathrm{l}}\right)$ than in the upwelling

219 radiation at the TOA $\left(R_{2}\right)$. This is because $R_{1}$ is more sensitive to the stratospheric

220 emissivity (ع) increase than $\mathrm{R}_{2}$. Consider a two-layer (troposphere and stratosphere) grey-

221 atmosphere model, $\partial \mathrm{R}_{/} / \partial \varepsilon$ equals $\sigma \mathrm{T}_{1}^{4}$, which is the blackbody emission at the

222 stratospheric temperature $T_{1}$, while $\partial \mathrm{R}_{2} / \partial \varepsilon$ equals $\sigma \mathrm{T}_{2}^{4}-\sigma \mathrm{T}_{1}^{4}$, which is the difference

223 between the blackbody emission at the equivalent troposphere-surface temperature $T_{2}$ and

224 that at the stratospheric temperature $T_{1}$. It can be shown that $T_{2}^{4}-T_{1}<T_{1}^{4}$ given that the

225 stratosphere is at radiative equilibrium and absorbs solar radiation. Secondly, the water

226 vapor feedback given in Table 1 is measured by the kernel method (Eq. 1) and reflects

227 only the emissivity effect of water vapor but not the indirect effect through stratospheric

228 cooling. The subsequent stratospheric cooling (decrease in $T_{1}$ ) due to the radiative cooling

229 caused by water vapor, however, will damp the emissivity effect on $R_{1}$ but enhance the

230 effect on $R_{2}$. If the stratosphere adjusts to a new radiative equilibrium, the overall changes

231 at the tropopause and at the TOA need to be balanced and thus the combined effect would 
232 be equal no matter whether it is evaluated at the TOA or tropopause. This means that the

233 sum of water vapor and temperature radiative effects by the end of the abrupt $4 \mathrm{xCO} 2$

234 experiment (when it approaches equilibrium), as given by Table 1, has appropriately

235 accounted for the combined water vapor radiative effects.

237 3.4 Combined feedback

238 The above results indicate that the stratosphere has a sign-uncertain temperature

239 feedback but a weak positive water vapor feedback. Adding the two effects yields a wide

240 range of feedback strengths with a minimum of $-0.06 \mathrm{~W} \mathrm{~m}^{-2} \mathrm{~K}^{-1}$ and a maximum of $0.07 \mathrm{~W}$

$241 \mathrm{~m}^{2} \mathrm{~K}^{-1}$. As a result, the MME is nearly zero, with a STD of $0.04 \mathrm{~W} \mathrm{~m}^{2} \mathrm{~K}^{-1}$ (Table 1).

242 Although the global mean feedback is insignificant, stratospheric changes play a non-

243 negligible role in local radiative feedback especially in extratropics (see Fig. 3).

244 To verify the feedback values obtained above using the differencing method

245 (Equations 1 and 2), we also calculate the feedback parameters using a regression method,

246 by regressing the global annual mean radiation anomalies in years $21-150$ in the

247 abrupt $4 \mathrm{xCO} 2$ experiment to the surface temperature anomalies. The results obtained from

248 the two methods are generally in agreement (see Table 1). The only noticeable

249 discrepancy in the CCSM4 model is due to weak linear relationship between the

250 stratospheric temperature-caused radiation anomaly and surface temperature anomaly

251 (and thus greater regression uncertainty). 


\section{4. Cause of local stratospheric feedback}

$254 \quad 4.1$ Temperature feedback

255 The analysis above indicates that the stratospheric temperature feedback is locally

256 significant in the extratropics (Figs. 2a and 3a). The stratospheric temperature response

257 shown in Figure 2a consists of both positive and negative changes. In general, the

258 positive signals emerge from both sides of the subtropical tropopause region and extend

259 poleward and upward in both hemispheres. This pattern of warming, looking like bull

260 horns, does not resemble the temperature change that is caused by stratospheric

261 moistening, which would be uniformly negative (e.g., Forster and Shine 1999). Instead,

262 one can draw similarities between the feedback temperature response here and the

263 temperature changes in many of the global warming experiments (e.g., Son et al. 2009),

264 which suggests a common cause of the bullhorn-like feedback response of the

265 stratospheric temperature.

266 We find that the bull horns-like temperature change pattern between $60 \mathrm{~S}$ and

$26760^{\circ} \mathrm{N}$ is very well correlated with the anomaly of the residual vertical velocity $w^{\prime \prime}$ (see

268 Andrews et al 1987, Eq. 3.5.1b for definition) in the stratosphere (compare Figs. 4a and

269 b). The increases of upwelling in the deep tropics and downwelling in the extropical

270 regions, as shown in Figure 3b, particularly indicate strengthening of the BDC in the

271 quadrupling $\mathrm{CO}_{2}$ experiment as in the scenario integrations (e.g., Butchart et al., 2006;

272 Manzini et al., 2014). The consequent adiabatic cooling and warming largely explain the

273 bullhorn pattern in the stratospheric temperature change. This result suggests that the 
274 peculiar stratospheric temperature feedback response likely results from the strengthening 275 of the BDC.

276 To verify that it is the SST-driven circulation change that gives rise to the

277 bullhorn-like temperature feedback response in the stratosphere, we conduct the

278 following experiment using CAM5 (Neale et al. 2010). The model is integrated from

2791960 to 2007 with greenhouse gas concentration fixed at 1960 value but with time-

280 varying historical SST values. Four ensemble runs are done. Figure $4 \mathrm{c}$ shows that this

281 experiment reproduces the bullhorn-shaped temperature response pattern seen in the

282 quadrupling $\mathrm{CO}_{2}$ experiment fairly well (compare Figs. 4a and 4c). Although temperature

283 trend in the Southern Hemisphere high latitudes is different, it is not statistically

284 significant.

285 We diagnose the temperature tendency terms $\left(\frac{d T}{d t}, \mathrm{~T}\right.$ : temperature; $\mathrm{t}:$ time $)$ in the

286 CAM5 simulations, including those caused by dynamics (heat advection) and physics

287 (the physical parameterizations of longwave and shortwave radiative heating, moist

288 processes, vertical diffusion, deep convective detrainment and orographic gravity wave

289 drag, etc). We find that the temperature tendency caused by the resolved dynamics, as

290 opposed to the parameterized physics, accounts for the bullhorn-shaped temperature

291 pattern. The pattern caused by the physics is dominated by radiative cooling, which is

292 spatially uniform, as shown by previous studies (Forster and Shine 1999), and does not

293 explain the bullhorn-shaped pattern. In comparison, the pattern caused by the dynamics

294 (Figure $4 \mathrm{~d}$ ) is also bullhorn-shaped and has a strong spatial correlation with the overall 
295 temperature trend pattern (correlation coefficient: 0.95). Moreover, the dynamically-

296 caused temperature change pattern is well correlated with the anomalous residual vertical

297 velocity $w^{*}$ between $60^{\circ} \mathrm{S}$ and $60^{\circ} \mathrm{N}$. The spatial correlation between the two variables is -

298 0.54; the temporal correlation between the annual mean anomalies of the two variables at

$29950 \mathrm{hPa}$ averaged over the tropics $\left(30^{\circ} \mathrm{S}-30^{\circ} \mathrm{N}\right)$ is -0.80 . These results affirm that surface

300 warming causes dynamics adjustment (BDC strengthening) in the stratosphere, which

301 then leads to the distinct temperature change pattern.

302 It is important to note that the positive and negative temperature changes caused

303 by the stratospheric circulation changes have compensating radiative effects over the

304 globe. Using the kernel approach (Eq. 1) the global-mean feedback effect due to the

305 dynamical term (Figure $4 \mathrm{~d}$ ) is calculated to be $-0.01 \mathrm{~W} \mathrm{~m}^{2} \mathrm{~K}^{-1}$. This affirms that the

306 dynamical heating/cooling does not lead to a significant feedback in the global-mean

307 surface temperature.

308

3094.2 Water vapor feedback

310 Unlike tropospheric water vapor variations, which can be largely explained by

311 tropospheric temperature change and conservation of relative humidity, stratospheric

312 water vapor is not controlled by local temperature. The water vapor and temperature

313 change patterns (Figure 2) in the abrupt $4 \mathrm{xCO} 2$ experiment bear no similarity in the

314 stratosphere. 
316 vapor increase occurs in the lowermost stratosphere that is adjacent to the tropical upper

317 troposphere region where the atmospheric moistening is maximized. This suggests that

318 the stratospheric moistening is through mixing (e.g., isentropic) that transports water

319 from tropical upper troposphere to lower stratosphere. Indeed, the global mean specific

320 humidity in the lowermost stratosphere (above tropopause and below $70 \mathrm{hPa}$ ) and the

321 tropical mean $\left(30^{\circ} \mathrm{S}-30^{\circ} \mathrm{N}\right)$ upper tropospheric specific humidity (UTH) averaged in a

$322100 \mathrm{hPa}$ layer below tropopause are strongly correlated. Table 2 shows that the

323 correlation between the annual anomalies of the two variables in every model is greater

324 than 0.9 (many close to 1 ).

325 The UTH control of the overworld stratosphere (above $70 \mathrm{hPa}$ ) is noticeably

326 weaker (see Table 2). For this region, it is expected that the ascent strength of the BDC

327 and the temperature at tropical cold point tropopause (CPT) also influence the

328 stratospheric humidity (Gettelman et al. 2010, Feuglistaler et al. 2014). Similar to what is

329 found by Dessler et al. (2014), we find strong anti-correlation (-0.81) between the

330 residual velocity $\mathrm{w}^{*}$ and the CPT temperature, which indicates that the two control factors

331 have degenerated to one (with compensating effects). We correlate the annual anomalies

332 of the CPT temperature and the stratospheric specific humidity in each model and find

333 significant correlation in some models. In comparison, the specific humidity in both

334 lowermost and overworld stratosphere is better explained by the UTH, except for the

335 MIROC5 model. We also conduct a multiple regression of the stratospheric humidity 
336 change against both variables: UTH and CPT. We find they together can explain most of

337 the stratospheric water vapor change in most models, except for the overworld

338 stratosphere in the INMCM4 model.

339 Finally, with regard to the inter-model differences in these variables, we find high

340 correlation between the global mean overall stratospheric water vapor change and the

341 tropical upper tropospheric water vapor change (correlation coefficient: 0.86 ), and the

342 tropical CPT temperature (0.67), respectively. In summary, these results suggest that the

343 moist increase in the lowermost stratosphere can be mostly attributed to mixing of upper

344 tropospheric water vapor, while that in the overworld is also affected by changes in BDC

345 strength and in tropical tropopause temperature.

$347 \quad$ 5. Discussion and conclusions

348 We analyze the stratospheric responses in climate models that can be considered

349 as a feedback to surface warming. The GCMs examined have a stratospheric temperature

350 feedback ranging from -0.09 to $+0.04 \mathrm{~W} \mathrm{~m}^{2} \mathrm{~K}^{-1}$ and a weaker water vapor feedback from

3510.01 to $0.03 \mathrm{~W} \mathrm{~m}^{-2} \mathrm{~K}^{-1}$. The sum of the two effects ranges from -0.06 to $0.07 \mathrm{~W} \mathrm{~m}^{-2} \mathrm{~K}^{-1}$ with

352 almost zero multi-model ensemble mean value. The high-end feedback magnitudes

353 suggest that the stratosphere may have a non-negligible effect on climate sensitivity. The

354 considerable range of the feedback values indicate that this feedback mechanism is

355 poorly quantified in the models. 
356 The overall climate feedback of the same CMIP5 models analyzed here amounts

357 to $-1.4 \pm 0.4 \mathrm{~W} \mathrm{~m}^{-2} \mathrm{~K}^{-1}$ (MME and STD, see Zhang and Huang, 2014). In comparison, the

358 stratospheric feedback makes considerably less contribution to the overall climate

359 feedback and its spread in these models. However, we note that the stratospheric

360 adjustment, i.e., the rapid stratospheric temperature change that is induced by $\mathrm{CO}_{2}$ cooling

361 and is not related to surface warming, has a much more significant impact on the

362 radiation energy budget (a MME of $1.9 \mathrm{~W} \mathrm{~m}^{-2}$, in comparison to a $5.4 \mathrm{~W} \mathrm{~m}^{-2}$ instantaneous

363 forcing of quadrupling $\mathrm{CO}_{2}$ ). It can be concluded that the significant inter-model spread

364 of the overall stratospheric radiative impact as noticed by Huang (2013b) can be mostly

365 attributed to forcing adjustment.

366 We also note that the results here do not exclude the possibility of stratospheric

367 feedback caused by mechanisms other than water vapor and temperature variations. For

368 instance, Zhou et al. (2014) find a non-negligible cirrus cloud feedback in short-term

369 climate variations in observational data (a fraction of which may be related to clouds

370 above the tropopause and thus be considered a stratospheric feedback), although this

371 feedback is insignificant in GCM global warming experiments (Zelinka et al., 2012).

372 With regard to the cause of stratospheric feedback, we find that the strengthening

373 of the BDC explains the stratospheric temperature feedback. The circulation change

374 causes the temperature change through both dynamical (via adiabatic heat advection) and

375 radiative (via changing stratospheric water vapor) heating. These two mechanisms are

376 characterized by distinctive zonal mean temperature change patterns. The dynamical 
377 heating pattern resembles the shape of bullhorns while the radiative heating pattern is

378 much more uniform. This suggests that it should be possible to attribute the overall

379 temperature change in both simulations and observation records to the two mechanisms

380 based on these distinctive spatial signatures, which shall be investigated in future work.

$381 \quad$ Unlike temperature feedback, stratospheric water vapor shows positive feedback

382 in all experiments. The stratospheric water vapor response largely results from

383 transported moisture from the tropical upper troposphere through mixing, but is also

384 modulated by cold point temperature as well as BDC strength. It warrants further

385 research to clarify how different mechanisms (e.g., ascent strength vs. tropopause

386 temperature) control the stratospheric water vapor change in a warming climate, at least

387 in the models. It should be borne in mind that not all 11 CMIP5 models included in this

388 analysis fully resolve the stratosphere. The high-top models seem to have a stronger

389 water vapor feedback (see Table 1) and this can be attributed to the relatively stronger

390 extropical lower stratospheric moistening, the effects of which are also stressed by

391 Dessler et al. (2013).

392 Although the net effect of global-mean stratospheric temperature and waver vapor

393 feedback is small, we find that stratospheric changes may be important for local radiative

394 feedback. A significant positive feedback is found in the extratropics. This could

395 effectively change meridional temperature gradient in the troposphere. Since the

396 circulation is sensitive to temperature gradient change in addition to temperature change

397 itself, this local radiative feedback can affect circulation in certain regions. This potential 
398 link between stratospheric feedback and tropospheric climate change needs to be

399 explored in future study.

400

401 Acknowledgements

402 We thank three anonymous reviewers whose comments helped improve the

403 quality of the paper. Y. Huang and MZ are supported by a Discovery grant form the

404 National Science and Engineering Research Council of Canada (RGPIN418305-13). YX

405 is supported by a postdoctoral fellowship of Fonds de recherché du Québec- Nature et

406 technologies. YX and Y. Hu are supported by the National Natural Science Foundation of

407 China (41025018) and by the National Basic Research Program of China (973 Program,

408 2010CB428606). SWS is supported by Korea Ministry of Environment as "Climate

409 Change Correspondence Program". We acknowledge the World Climate Research

410 Programme's Working Group on Coupled Modelling for the CMIP5 model data used in

411 this study. 


\section{References}

413 Butchart, N., and Coauthors, 2006: Simulations of anthropogenic change in the strength of the

414 Brewer-Dobson circulation. Climate Dyn., 27, 727-741, doi:10.1007/s00382-006-0162-4.

415 Bunzel, F., and H. Schmidt, 2013: The Brewer-Dobson circulation in a changing climate: Impact

416 of the model configuration. Journal of the Atmospheric Sciences, 70(9), 3002-3002.

417 Dessler, A. E., Schoeberl, M. R., Wang, T., Davis, S. M., \& Rosenlof, K. H. , 2013, Stratospheric

418 water vapor feedback. Proceedings of the National Academy of Sciences, 110(45), 18087-18091.

419 Dessler, A. E., M. R. Schoeberl, T. Wang, S. M. Davis, K. H. Rosenlof, and J.-P. Vernier, 2014,

420 Variations of stratospheric water vapor over the past three decades, J. Geophys. Res. Atmos.,

421 119, 12,588-12,598, doi:10.1002/2014JD021712.

422 Forster, P. M. D. and K. P. Shine, 1999. "Stratospheric water vapour changes as a possible

423 contributor to observed stratospheric cooling." Geophysical Research Letters 26(21): 3309-3312.

424 Fueglistaler, S., et al., 2014, Departure from Clausius-Clapeyron scaling of water entering the

425 stratosphere in response to changes in tropical upwelling, J. Geophys. Res. Atmos., 119, 1962-

426 1972, doi:10.1002/2013JD020772.

427 Gerber et al., 2012: Assessing and understanding the impact of stratospheric dynamics

428 and variability on the earth system. Bull. Amer. Meteor. Soc., 93, 845-859.

429 Gettelman, A., et al. , 2010, Multimodel assessment of the upper troposphere and lower 430 stratosphere: Tropics and global trends, J. Geophys. Res., 115, D00M08, 431 doi:10.1029/2009JD013638.

432 Hansen, J., M. Sato, and R. Ruedy, 1997: Radiative forcing and climate response. J. 433 Geophys. Res. Atmos., 102, 6831-6864. 
434 Hegglin, M. I., Tegtmeier, S., Anderson, J., Froidevaux, L., Fuller, R., Funke, B., ... \& 435 Weigel, K., 2013, SPARC Data Initiative: Comparison of water vapor climatologies from 436 international satellite limb sounders. Journal of Geophysical Research: Atmospheres, $437118(20), 11-824$.

438 Huang, Y., V. Ramaswamy, and B. Soden, 2007:An investigation of the sensitivity of the clear439 sky outgoing longwave radiation to atmospheric temperature and water vapor, J. Geophys. Res., 440 112, D05104,doi:10.1029/2005JD006906.

441 Huang, Y., 2013a: A simulated climatology of spectrally decomposed atmospheric infrared 442 radiation, J. of Climate, doi: 10.1175/JCLI-D-12-00438.1.

443 Huang, Y., 2013b: On the Longwave Climate Feedbacks. Journal of Climate 26(19): 7603-7610.

444 Huang, Y. and M. Zhang, 2014: The implication of radiative forcing and feedback for 445 meridional energy transport, Geophys. Res. Lett., DOI: 10.1002/2013GL059079.

446 Joshi, M. M., M. J. Webb, et al., 2010. "Stratospheric water vapour and high climate sensitivity 447 in a version of the HadSM3 climate model." Atmospheric Chemistry and Physics 10(15): 71614487167.

449 Li, F., J. Austin, and R. J. Wilson, 2008:The strength of the Brewer-Dobson circulation in a 450 changing climate: coupled chemistry-climate model simulations, J. Clim., 21, 40-57.

451 Manzini, E., et al., 2014:Northern winter climate change: Assessment of uncertainty in 452 CMIP5 projections related to stratosphere-troposphere coupling, J. Geophys. Res. 453 Atmos., 119, doi:10.1002/2013JD021403.

454 McClatchey, R. A., R. W. Fenn, J. E. Selby, F. E. Volz, and J. S. Garing, 1972:Optical 455 Properties of the Atmosphere, Third Edition, Air 599 Force Geophysical Laboratory 456 Technical Report, AFCRL-72-0497, 80 pp. 
457 McLandress, C., and T. G. Shepherd, 2009: Simulated Anthropogenic Changes in the Brewer458 Dobson Circulation, Including Its Extension to High Latitudes. J. Climate, 22, 1516-1540. doi: $459 \quad 10.1175 / 2008 J C L I 2679.1$

460 Mote, P. W., K. H. Rosenlof, et al., 1996. "An atmospheric tape recorder: The imprint of tropical 461 tropopause temperatures on stratospheric water vapor." Journal of Geophysical Research 462 101(D2): 3989.

463 Neale, R. B., and Coauthors, 2010: Description of the NCAR Community Atmosphere Model 464 (CAM5.0). NCAR Tech. Rep. NCAR/TN-486+STR, 268 pp.

465 Shell, K. M., J. T. Kiehl, et al., 2008: "Using the radiative kernel technique to calculate climate 466 feedbacks in NCAR's Community Atmospheric Model." Journal of Climate 21(10): 2269-2282.

467 Shepherd, T. G., and C. McLandress, 2011: A robust mechanism for strengthening of the 468 brewer-dobson circulation in response to climate change: critical-layer control of subtropical 469 wave breaking. J. Atmos. Sci., 68, 784-797. doi: 10.1175/2010JAS3608.1

470 Brian J. Soden and Isaac M. Held, 2006: An Assessment of Climate Feedbacks in 471 Coupled Ocean-Atmosphere Models. J. Climate, 19, 3354-3360.

472 Soden, B. J., I. M. Held, R. Colman, K. M. Shell, J. T. Kiehl, and C. A. Shields, 473 2008:Quantifying climate feedbacks using radiative kernels. J. Clim., 21, 3504-3520.

474 Son, S.-W., L. M. Polvani, et al., 2009. "The Impact of Stratospheric Ozone Recovery on 475 Tropopause Height Trends." Journal of Climate 22(2): 429-445.

476 Stuber, N., M. Ponater, et al., 2001. "Is the climate sensitivity to ozone perturbations enhanced 477 by stratospheric water vapor feedback?" Geophysical Research Letters 28(15): 2887-2890.

478 Taylor, K. E., R. J. Stouffer, et al., 2011. "An Overview of CMIP5 and the Experiment Design." 479 Bulletin of the American Meteorological Society 93(4): 485-498. 
480 WMO, 1957: Definition of the tropopause. WMO Bull., 6, 136.

481 Zelinka, M., et al., 2012: Computing and Partitioning Cloud Feedbacks Using Cloud 482 Property Histograms. Part I: Cloud Radiative Kernels, J. Climate, 25, 3715-3735, 483 doi:10.1175/JCLI-D-11-00248.1.

484 Zhang, M., Y. Huang, 2014: Radiative forcing of quadrupling $\mathrm{CO}_{2}$, J. Climate, doi: 485 http://dx.doi.org/10.1175/JCLI-D-13-00535.1.

486 Zhou, C., A. E. Dessler, M. D. Zelinka, P. Yang, and T. Wang, 2014: Cirrus feedback on 487 interannual climate fluctuations, Geophys. Res. Lett., 41, doi:10.1002/2014GL062095. 
488 Tables

489 Table 1. Stratospheric temperature and water vapor feedback parameters of each model in

490 the unit of $\mathrm{W} \mathrm{m}^{2} \mathrm{~K}^{-1}$. Two methods are used here: a differencing method and a regression

491 method (see details in the texts). The results are grouped to high-top (HT, at $1 \mathrm{hPa}$ or

492 above) and low-top (LT) models. See Table 9.A.1 of the IPCC $5^{\text {th }}$ assessment report for

493 details of the models.

494

\begin{tabular}{|c|c|c|c|c|c|c|c|}
\hline \multirow{2}{*}{ MODEL } & \multirow{2}{*}{$\begin{array}{c}\text { Model } \\
\text { top }\end{array}$} & \multicolumn{3}{|c|}{ Differencing Method } & \multicolumn{3}{|c|}{ Regression Method } \\
\cline { 3 - 8 } & $\lambda_{\text {Tst }}$ & $\lambda_{\text {wVst }}$ & $\lambda_{\text {st }}$ & $\lambda_{\text {Tst }}$ & $\lambda_{\text {Wvst }}$ & $\lambda_{\text {st }}$ \\
\hline GFDL-CM3 & HT & -0.02 & 0.03 & 0.01 & -0.02 & 0.03 & 0.01 \\
\hline IPSL-CM5A-LR & HT & 0.04 & 0.03 & 0.07 & 0.06 & 0.02 & 0.08 \\
\hline MPI-ESM-MR & HT & 0.01 & 0.03 & 0.03 & 0.01 & 0.02 & 0.03 \\
\hline MRI-CGCM3 & HT & -0.09 & 0.03 & -0.06 & -0.07 & 0.03 & -0.04 \\
\hline CanESM2 & HT & -0.03 & 0.03 & -0.01 & -0.03 & 0.02 & -0.01 \\
\hline CCSM4 & LT & -0.06 & 0.01 & -0.05 & 0.00 & 0.01 & 0.01 \\
\hline CSIRO-Mk3.6.0 & LT & 0.03 & 0.01 & 0.04 & 0.04 & 0.00 & 0.04 \\
\hline HadGEM2-ES & LT & 0.02 & 0.02 & 0.04 & 0.06 & 0.02 & 0.07 \\
\hline INMCM4 & LT & -0.03 & 0.01 & -0.01 & -0.02 & 0.02 & 0.00 \\
\hline MIROC5 & LT & -0.02 & 0.01 & -0.01 & -0.01 & 0.02 & 0.01 \\
\hline NorESM1-M & LT & -0.01 & 0.01 & -0.00 & 0.01 & 0.01 & 0.02 \\
\hline Mean & & -0.02 & 0.02 & 0.00 & 0.01 & 0.02 & 0.02 \\
\hline STD & & 0.04 & 0.01 & 0.04 & 0.04 & 0.01 & 0.04 \\
\hline
\end{tabular}

495 
496 Table 2. Correlation between global mean lowermost (below 70hPa) and overworld

497 (above 70hPa) stratospheric specific humidity and two control factors: temperature at the

498 cold point tropopause (CPT) averaged over $10^{\circ} \mathrm{S}-10^{\circ} \mathrm{N}$ and tropical upper tropospheric

499 specific humidity (UTH) averaged over $30^{\circ} \mathrm{S}-30^{\circ} \mathrm{N}$. The correlation coefficients are

500 calculated based on the annual mean anomalies of these variables in Years 21-150 in the

501 abrupt $4 \mathrm{xCO} 2$ experiment for each model. In the case of CPT+UTH, stratospheric

502 specific humidity is first regressed to the two variables in a multiple regression and then

503 correlation coefficient is calculated between GCM-simulated and regression-model-

504 predicted humidity anomalies.

505

\begin{tabular}{|c|c|c|c|c|c|c|c|}
\hline \multirow{2}{*}{ MODEL } & \multirow{2}{*}{$\begin{array}{c}\text { Model } \\
\text { top }\end{array}$} & $\begin{array}{c}|c| \\
\text { CPT }+ \\
\text { UTH }\end{array}$ & CPT & UTH & $\begin{array}{c}\text { CPT }+ \\
\text { UTH }\end{array}$ & CPT & UTH \\
\hline GFDL-CM3 & HT & 0.99 & -0.07 & 0.99 & 0.92 & 0.13 & 0.89 \\
\hline IPSL-CM5A-LR & HT & 0.99 & -0.33 & 0.99 & 0.91 & -0.30 & 0.91 \\
\hline MPI-ESM-MR & HT & 0.99 & -0.25 & 0.99 & 0.87 & 0.18 & 0.77 \\
\hline MRI-CGCM3 & HT & 0.97 & 0.92 & 0.97 & 0.87 & 0.83 & 0.87 \\
\hline CanESM2 & HT & 0.99 & -0.06 & 0.99 & 0.86 & 0.01 & 0.86 \\
\hline CCSM4 & LT & 0.97 & 0.26 & 0.97 & 0.86 & 0.32 & 0.86 \\
\hline CSIRO-Mk3.6.0 & LT & 0.99 & 0.94 & 0.99 & 0.96 & 0.92 & 0.95 \\
\hline HadGEM2-ES & LT & 0.98 & -0.97 & 0.98 & 0.95 & -0.91 & 0.95 \\
\hline INMCM4 & LT & 0.91 & 0.34 & 0.91 & 0.37 & -0.05 & 0.36 \\
\hline MIROC5 & LT & 0.98 & 0.95 & 0.97 & 0.75 & 0.72 & -0.57 \\
\hline NorESM1-M & LT & 0.97 & 0.39 & 0.97 & 0.85 & 0.40 & 0.85 \\
\hline
\end{tabular}


(a) sstclim $4 \times \mathrm{CO} 2$

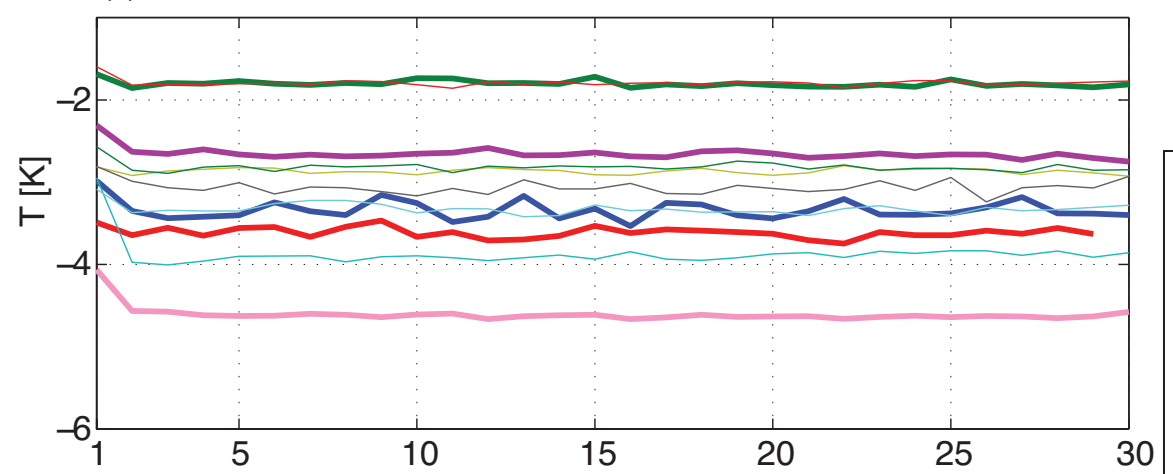

(b) abrupt4xCO2

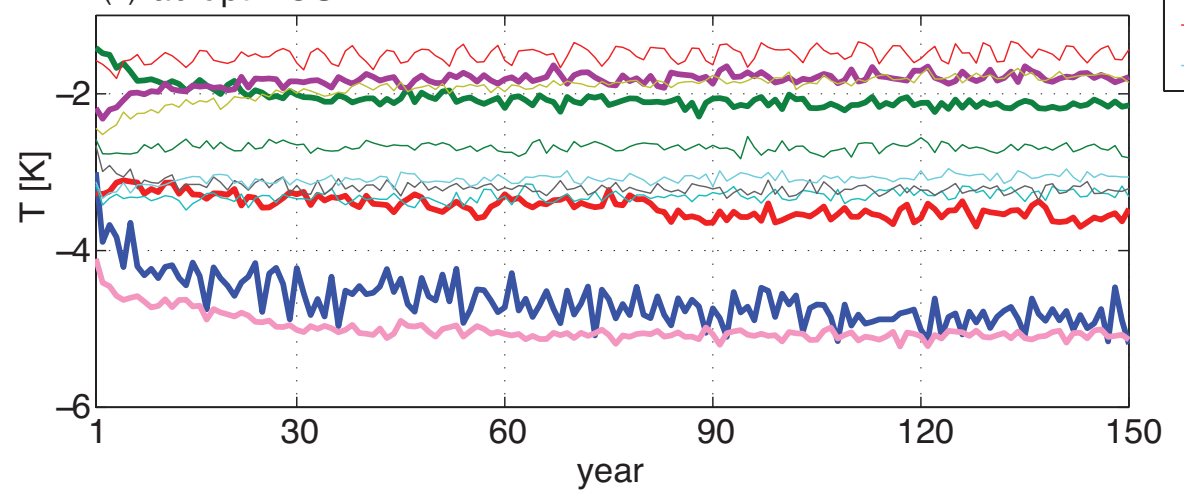

\begin{tabular}{|c|}
\hline GFDL-CM3 \\
IPSL-CM5A-LR \\
HadGEM2-ES \\
CCSM4 \\
CanESM2 \\
MRI-CGCM3 \\
MPI-ESM-MR \\
CSIRO-Mk3-6-0 \\
INM-CM4 \\
MIROC5 \\
NorESM1-M \\
\hline
\end{tabular}

511 Figure 1 . Time series of global mean $50 \mathrm{hPa}$ temperature change in the sstClim $4 \mathrm{xCO} 2$

512 (top) and abrup4xCO2 (bottom) experiments. The changes (unit: $\mathrm{K}$ ) are relative to their

513 control runs sstClim and piControl, respectively. Note that the range of x-axis is different

514 in two time series.

515 


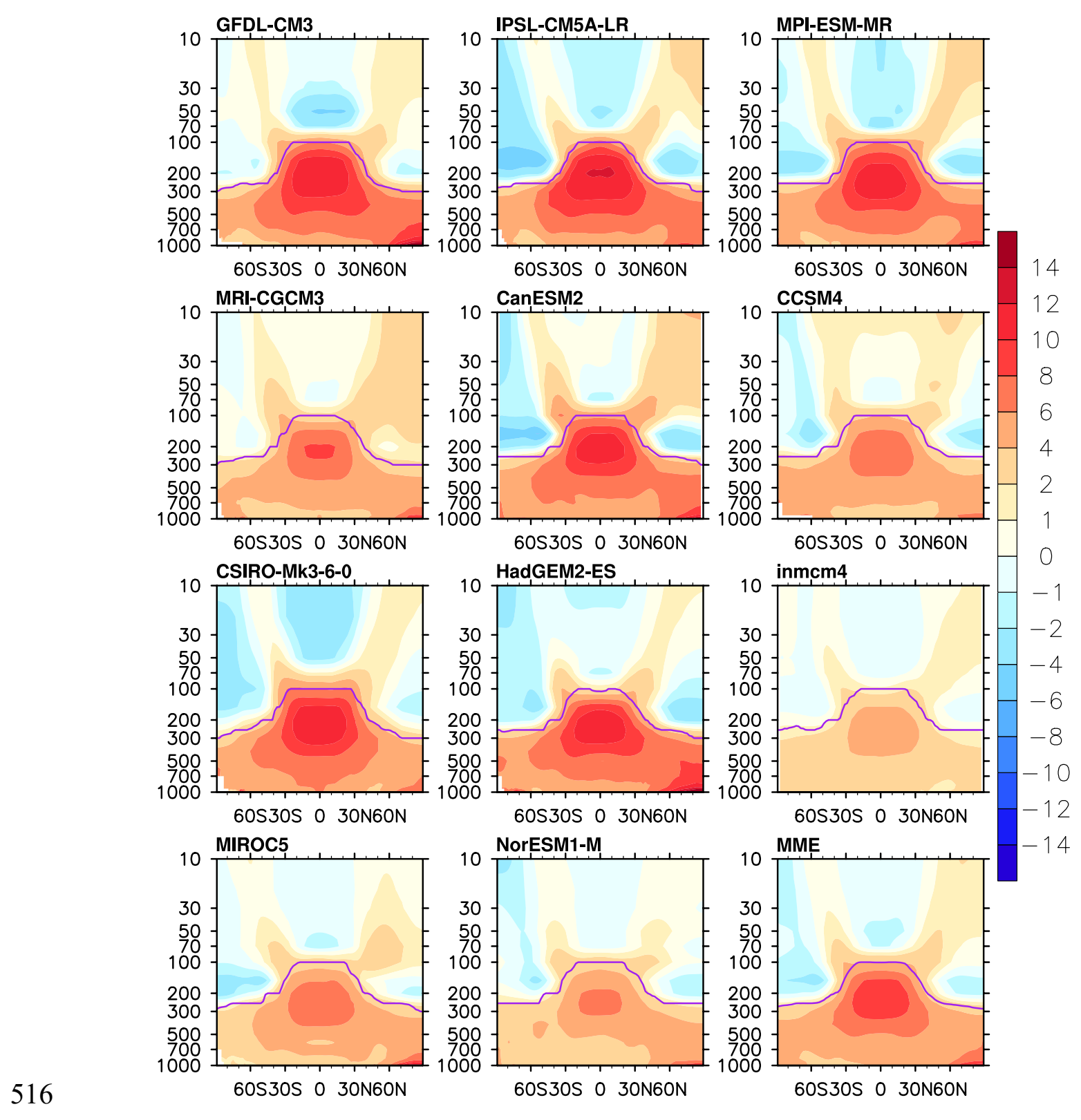

517 Figure 2. Zonal mean feedback response in a) atmospheric temperature $\Delta \mathrm{T}$, unit: $\mathrm{K}$, and b)

$518 \operatorname{logarithm}$ of specific humidity, $\Delta \log _{2}(\mathrm{q})$. The thick line indicates the tropopause. 


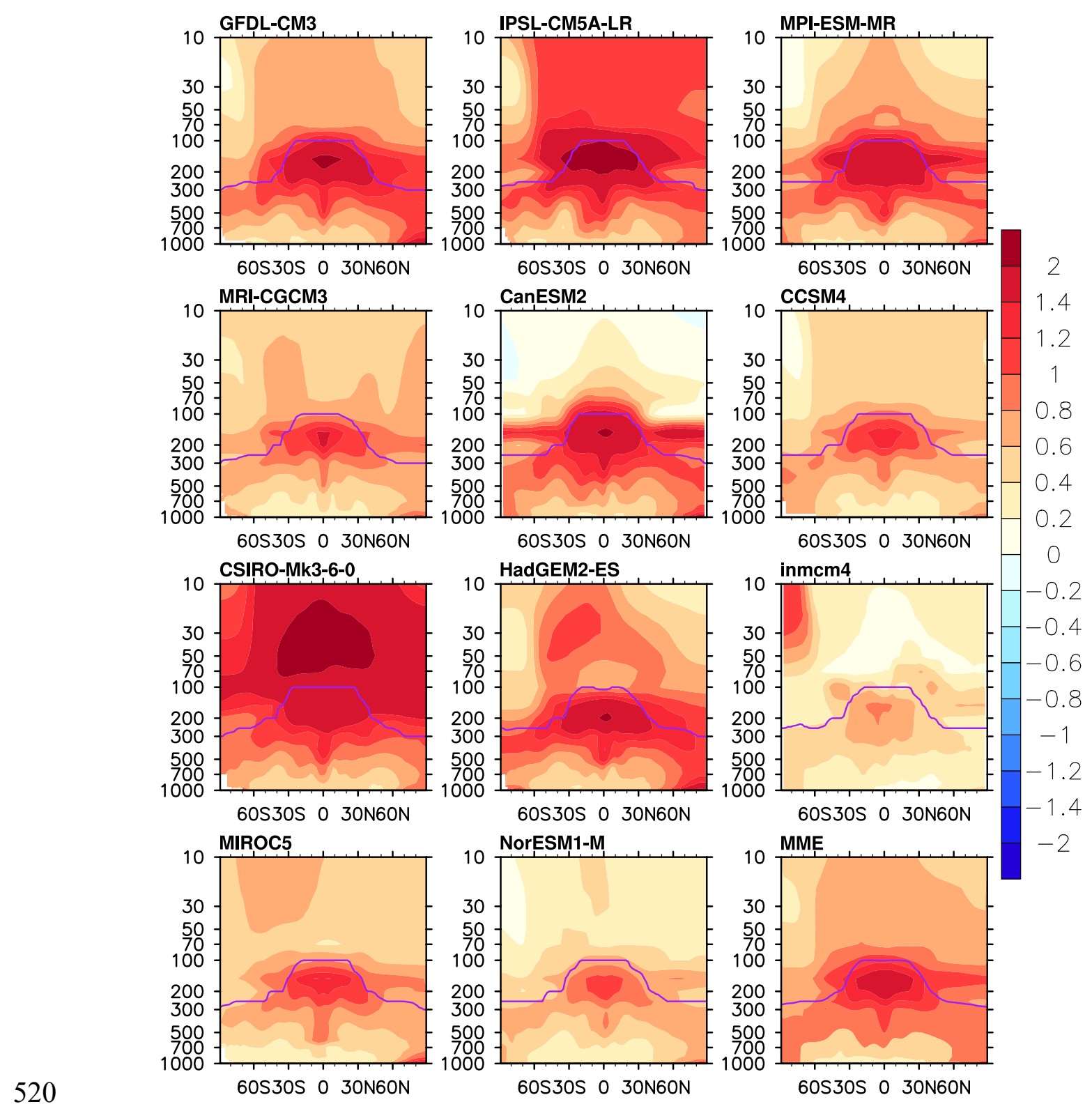

521 Figure 2 b. Zonal mean feedback response in the logarithm of specific humidity, $\Delta \log _{2}(q)$. 
(a) Temperature feedback

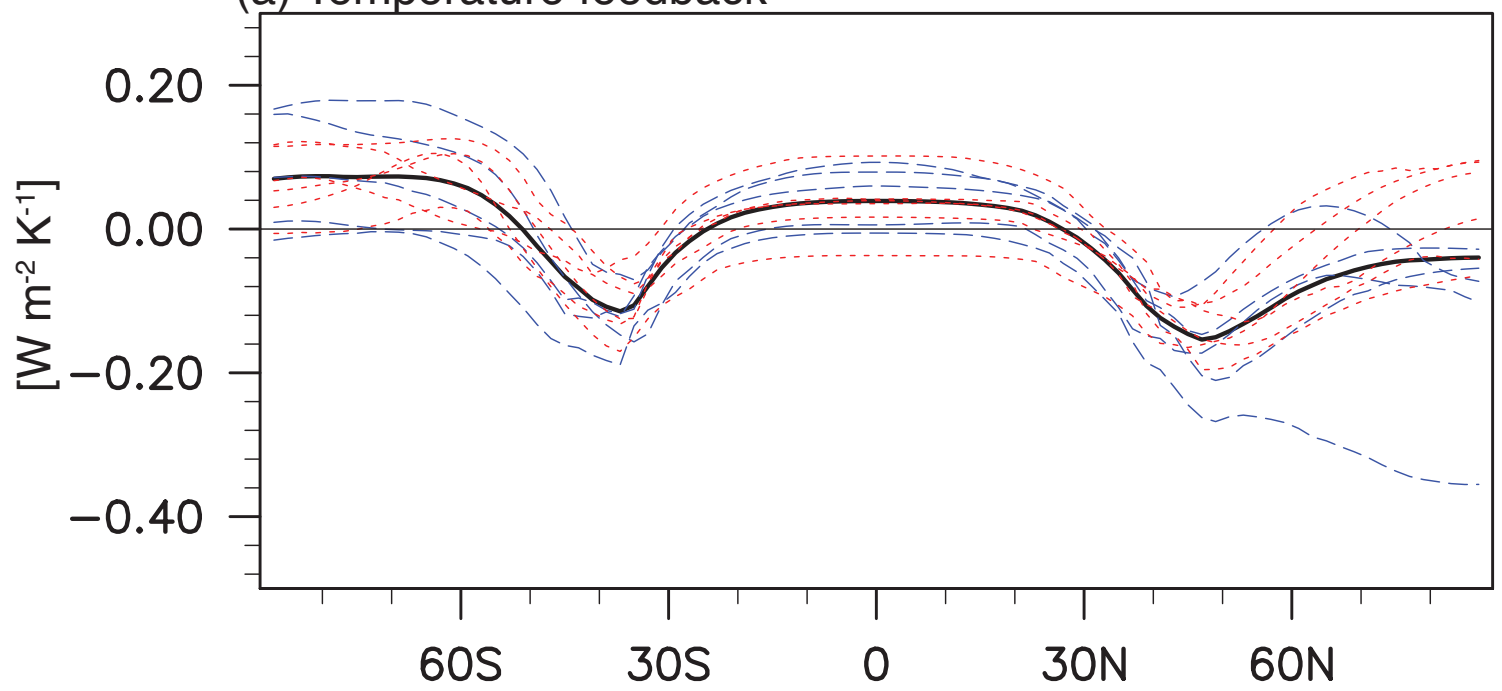

(b) Water vapor feedback

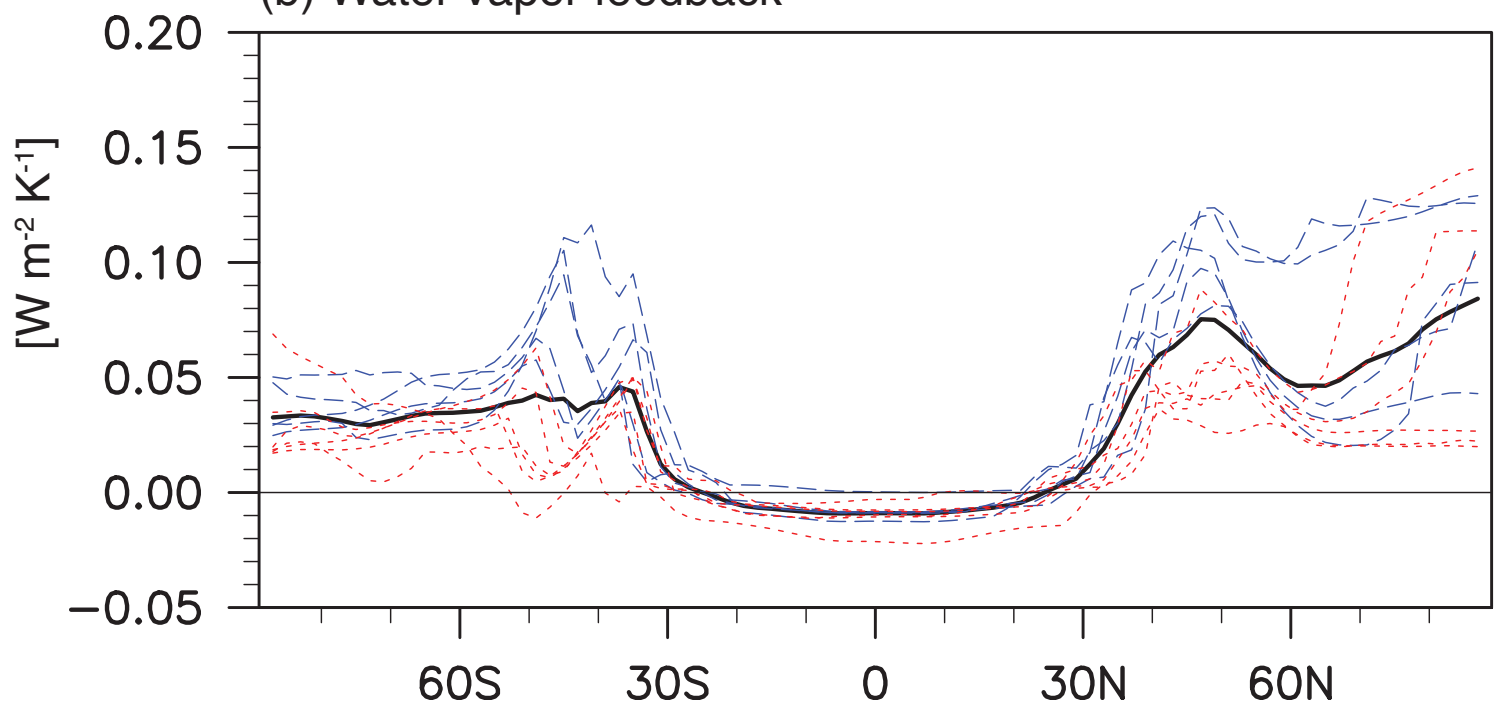

524 Figure 3. Zonal mean radiative feedbacks (unit: $\mathrm{W} \mathrm{m}^{-2} \mathrm{~K}^{-1}$ ) of the stratospheric a)

525 temperature and b) water vapor. The high- and low-top models are denoted by blue and

526 red dashed lines respectively. The thick black line denotes the multi-model mean. 


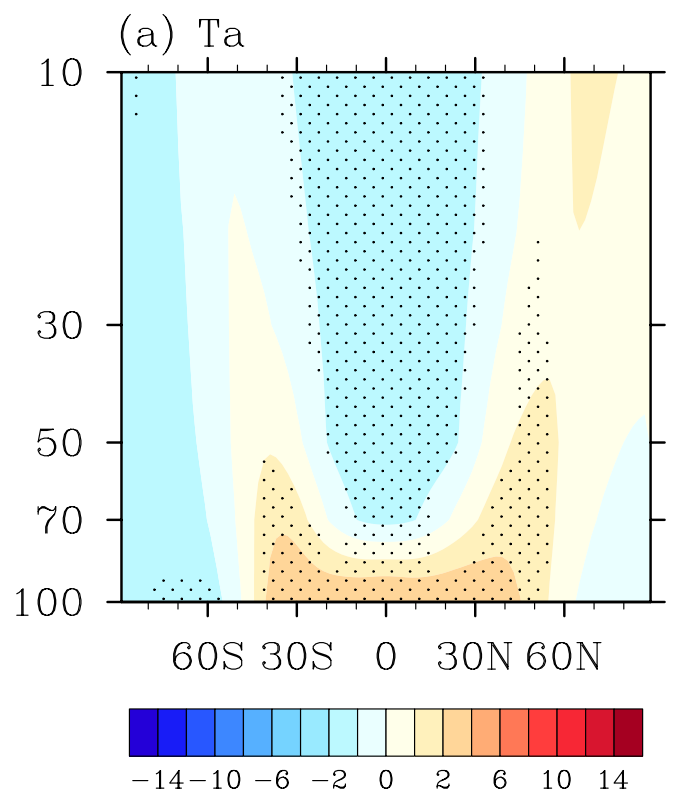

(b) $\mathrm{w}^{*}$
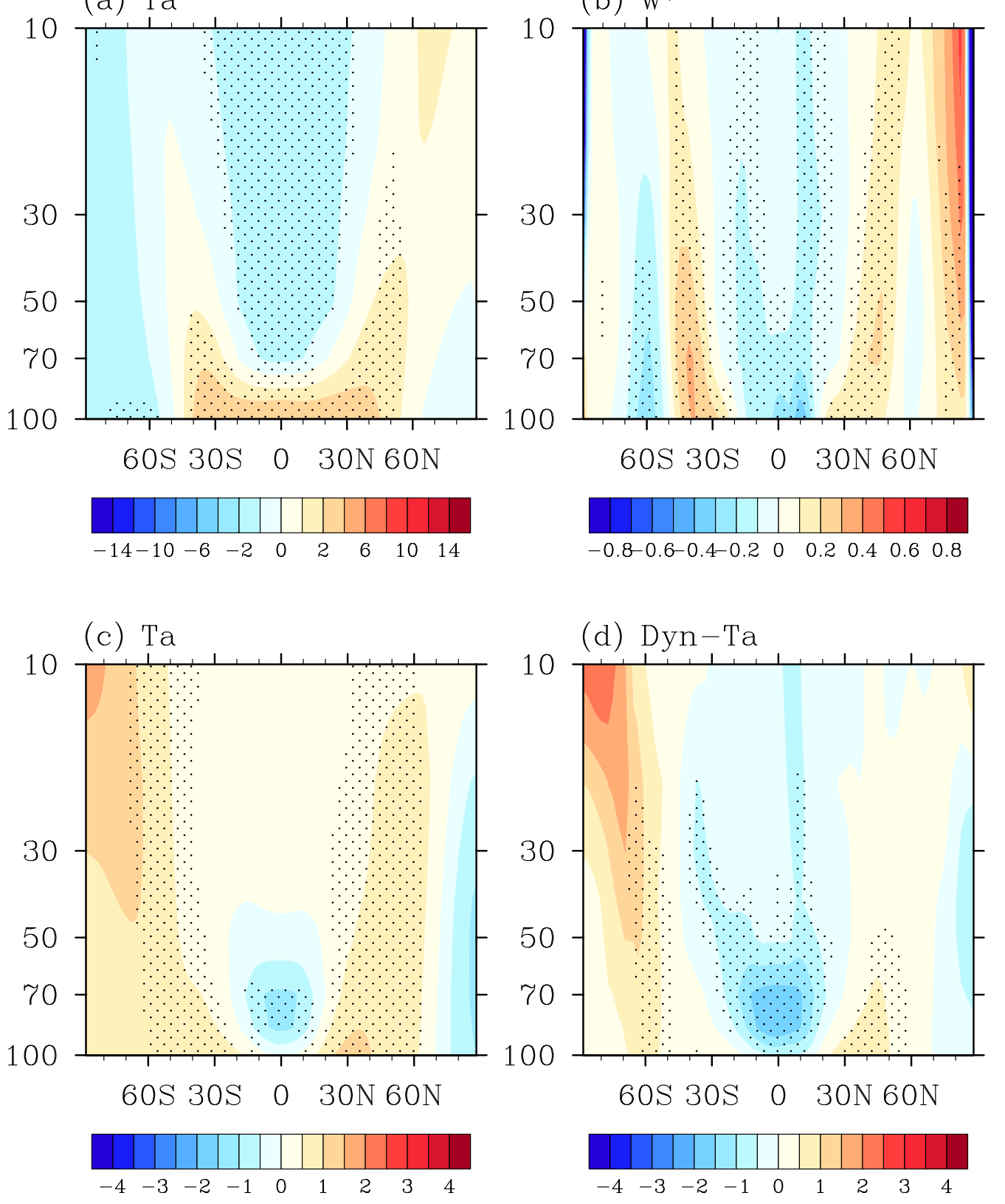

529 Figure 4. a) Multi-model mean feedback temperature response (unit: K) in the

530 abrupt $4 \mathrm{xCO}_{2}$ experiment. b) Multi-model mean change in the residual vertical velocity $w^{*}$ 
531 of the overturning circulation in the abrupt $4 \mathrm{xCO}_{2}$ experiment (unit: $\mathrm{mm} / \mathrm{s}$ ). Contoured

532 here is $(-1) \times \Delta w^{*}$, so that negative (positive) means ascent (descent). c) The ensemble

533 mean feedback temperature response (unit: K) in the CAM5 experiment. d) The dynamics

534 contribution to the temperature response (unit: K) in c). For the CAM5 experiment, the

535 change is the difference between the means of 2003-2007 and 1960-1964. In (a) and (b),

536 stippling indicates at least 13 models showing the same sign of change; in (c) and (d),

537 significant trend at $90 \%$ confidence level.

538 